\title{
Spawanie orbitale wężownic ze stali VM12-SHC
}

\author{
Orbital welding of steel coils VM12-SHC
}

\section{Streszczenie}

W pracy przedstawiono wybrane aspekty technologii wykonywania powierzchni grzewczych tj. wężownic przegrzewaczy pary z wykorzystaniem kompleksowego stanowiska do spawania metodą zmechanizowaną TIG. Próby spawania wykonano na rurach ze stali VM12-SHC o średnicy 44,5mm i grubości ścianki 7,1 mm. Przedstawiono wyniki badań niszczących oraz nieniszczących oraz wskazano na problemy jakie można spotkać w czasie spawania tego typu stali.

Przeprowadzone próby spawania złącza doczołowego dowiodły, iż spawanie orbitalne metodą TIG jest procesem bardzo skutecznym pod względem powtarzalności oraz jakości wykonanych połączeń spawanych. Odpowiednio przygotowane oprogramowanie procesu spawania, czy też bieżąca kontrola stanu technicznego urządzenia, powodują iż wskaźnik wadliwość wykonywanych złącz wynosi poniżej 1\%. Z tego względu metoda spawania orbitalnego TIG jest rekomendowana w przypadku, gdy spawane są elementy w gatunkach o utrudnionej spawalności tj. VM12-SHC.

Słowa kluczowe: spawanie orbitalne, stal VM12-SHC
Abstract

The paper presents selected aspects of technology performance of the heating surfaces, ie. steam superheater coils using a comprehensive outcome for mechanized TIG welding. Welding was carried out on steel pipes VM12-SHC having a diameter of $44,5 \mathrm{~mm}$ and a wall thickness $7,1 \mathrm{~mm}$. The results of destructive and non-destructive tests were presented and the problems that can be encounter during this type of welding steel were pointed out.

The butt joint welding tests that were made have proved that orbital TIG welding is a process very effective in terms of reproducibility and the quality of the welded joints. Properly prepared welding process software or the current control of the technical condition of the appliance, cause that the impairment indicator of the performed connectors is less than $1 \%$. Therefore, the orbital TIG welding method is recommended when the elements are welded in the species hindered weldability, ie. VM12-SHC.

Keywords: orbital welding, steel VM12-SHC

\section{Wstęp}

Rozwój energetyki w Polsce jak też w pozostałych krajach Uni Europejskiej opiera się głównie na modernizacji istniejących kotłów oraz budowie nowych kotłów do pracy w warunkach nadkrytycznych. Plan rozwoju na najbliższe lata zakłada osiągnięcie temperatury wylotowej pary na poziomie około $620 \div 650{ }^{\circ} \mathrm{C}$, a ciśnienie $28 \div 30 \mathrm{MPa}$. Osiągnięcie tak wysokich parametrów uzależnione jest od rozwoju materiałów hutniczych, od których wymaga się wysokich właściwości w podwyższonej temperaturze oraz zachowania dobrej spawalności tych materiałów. Większość ze stosowanych obecnie gatunków stali przeznaczonych do pracy w podwyższonej temperaturze to stale o strukturze marten-

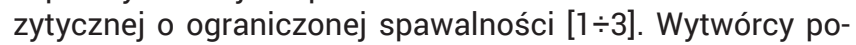
dejmujący się wytarzania urządzeń energetycznych z tych stali muszą wykazać się wysoką kulturą techniczną i z uwagi na ograniczoną spawalność stosować dodatkowe zabiegi cieplne jak podgrzewanie wstępne przed spawaniem, kontrola temperatury międzyściegowej oraz obróbka cieplna po spawaniu. Materiały hutnicze przeznaczone do wytwarzania wężownic przegrzewaczy powinny charakteryzować się zdolnością do przenoszenia krótko- lub długotrwałych obciążeń (stałych lub zmiennych) w wysokiej temperaturze, dobrą spawalnością, odpowiednią wytrzymałością na pełzanie oraz odpornością na korozję i utlenianie. Stale martenzytyczne typu T/P91 o zawartości $9 \%$ chromu po raz pierwszy wdrożono do produkcji kolektorów oraz wężownic w latach osiemdziesiątych. Dalsze analizy oraz badania prowadzone na stali T/P91 doprowadziły do powstania kolejnych gatunków tj. P92 oraz E911, w których molibden został zastąpiony wolframem. Zmiana składu chemicznego wpłynęła na zwiększenie odporności na pełzanie oraz umożliwiła pracę elementów ciśnieniowych w temperaturze do około $620^{\circ} \mathrm{C}$. Pomimo poprawy własności mechanicznych zastosowanej stali w wyniku pracy w podwyższonych temperaturach w dalszym ciągu występowało zjawisko utleniania oraz korozji co w znacznym stopniu ograniczyło zastosowanie tych stali w nowoczesnych kotłach. Zapotrzebowanie na stal, która odznaczałaby się zarówno odpowiednią wytrzymałością na pełzanie oraz odpornością na utlenianie doprowadziło do opracowania w Japonii i USA stali P122 o zawartości 12\% chromu z dodatkiem molibdenu i wolframu. Obecnie w fazie rozwoju są gatunki zawierające $2,5 \%$ kobaltu $2,6 \%$ wolframu

\section{Dr inż. Marek Gucwa, dr inż Robert Bęczkowski - Politechnika Częstochowska; mgr inż Marcin Stefański.}


i boru tj. NF12 oraz SAVE1 2 zawierająca 3\% kobaltu, 3\% wolframu oraz dodatki tantalu i niobu. Odpowiednikiem stali o zawartości 12\% chromu jest opracowana przez Vallourec \& Mannesmann stal VM12-SHC. Stal ta zawierająca $12 \%$ chromu może być eksploatowana w temperaturze do $650{ }^{\circ} \mathrm{C}$. Częściowe zastąpienie molibdenu wolframem, powoduje wzrost wytrzymałości na pełzanie o około $30 \%$ oraz zwiększa hartowność stali, natomiast mikrododatek w postaci boru ma za zadanie stabilizację węglików M23C6. Niska zawartość węgla w porównaniu do stali X20 gwarantuje dobrą spawalność oraz zapobiega powstawaniu pęknięć wodorowych $[1 \div 6]$.

Rosnące wymagania odnośnie jakości wykonywanych złączy również wpływają na dynamiczny rozwój techniki spawalniczej, która ma gwarantować wysoką jakość otrzymywanych złączy oraz powtarzalność procesu [7]. Spawanie orbitalne TIG jest techniką powszechnie uznaną w przemyśle, a firmy takie jak np. Polysoude, Fronius, ESAB oraz Orbitec, posiadają $\mathrm{W}$ swoim asortymencie oprócz źródeł zasilania i głowic spawalniczych inne urządzenia pomocnicze typu pozycjonery i manipulatory czy też sprzęt do obróbki mechanicznej. Spawanie orbitalne jest procesem zmechanizowanym, prowadzonym za pośrednictwem specjalnie przystosowanych do tego celu głowic spawalniczych przemieszczających się względem złącza na taśmie lub listwie zębatej, wyposażonych w mikroprocesorowe układy sterowania. Technika spawania orbitalnego jest wykorzystywana m.in. do wykonywania rurociągów, wężownic i innych konstrukcji rurowych wykorzystanych w przemyśle energetycznym, ciepłowniczym lub chemicznym. W technice spawania orbitalnego mogą być wykorzystywane różne metody spawania. W przypadku elementów rurowych o małych średnicach zewnętrznych bądź małych grubościach ścianek rekomendowaną metodą jest spawanie łukowe elektrodą nietopliwą w osłonie gazów obojętnych - TIG. Spawanie orbitalne metodą TIG może być prowadzone bez dodatku spoiwa, jak i z jego udziałem w zależności od geometrii przekroju poprzecznego rury [3].

\section{Materiał do badań i próby spawania}

Przedmiotem badań było złącze doczołowe z rury o średnicy 44,5 mm i grubości ścianki 7,1 mm ze stali X12CrCoWVNb12-2-2 (VM12-SHC) o składzie chemicznym podanym $w$ tablicy I. Do spawania zmechanizowanego metodą TIG wykorzystano urządzenie firmy Polysoude składające się ze źródła prądu PS 406 oraz głowicy otwartej MU IV80. Jako materiału dodatkowego do spawania wykorzystano spoiwo Thermanit MTS 5CoT (tabl. II). Do spawania jako gaz osłonowy wykorzystano argon z natężeniem przepływu $10 \div 12 \mathrm{l} / \mathrm{min}$ oraz użyto go również jako gazu formującego z natężeniem przepływu $4 \div 6 \mathrm{l} / \mathrm{min}$.

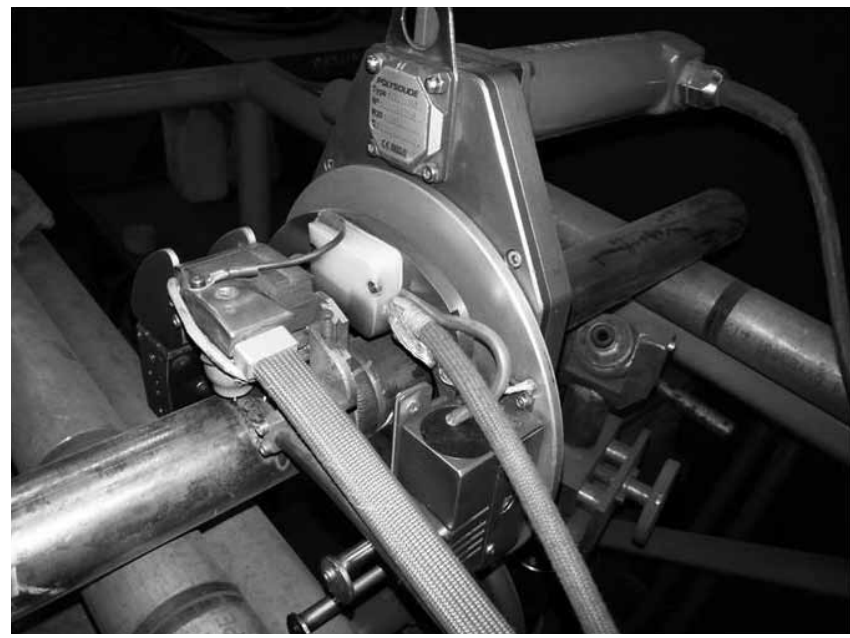

Rys. 1. Głowica spawalnicza otwarta typu MU IV 80

Fig. 1. Open weld head MU IV 80

W celu uzyskania regularnego przetopu przygotowano rowek spawalniczy w kształcie U. Średnica wewnętrzna rury została obrobiona mechanicznie, uzyskując jednakową wysokości progu z dopuszczalną tolerancją wymiarową $\pm 0,1$ do $0,3 \mathrm{~mm}$.

Ze względu na ruch palnika wokół osi spawanego złącza, proces przeprowadzono w następujących pozycjach spawania: PA, PG, PE, PF wg. EN ISO 6947.

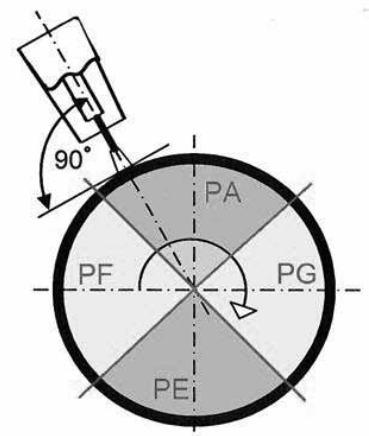

Rys. 2. Układ pozycji na obwodzie spawanej rury [6]

Fig. 2. Layout position on the circumference of welded pipe [6]

Przed procesem spawania, rura została podgrzana do temperatury $200 \div 250{ }^{\circ} \mathrm{C}$ w celu zapobiegania pęknięciom wodorowym. W trakcie procesu spawania na bieżąco kontrolowano temperaturę międzyściegową, która wynosiła maksymalnie $280^{\circ} \mathrm{C}$. Z uwagi na grubość ścianki, wynoszącą 7,1 mm, spoina była wykonywana wielościegowo i składa się z 5 następujących warstw:

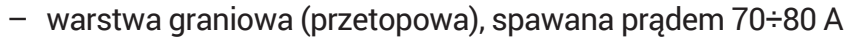

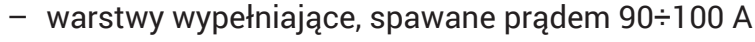

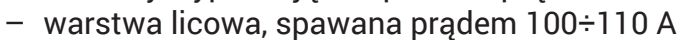

Tablica I. Skład chemiczny stali VM12-SHC [4]

Table I. Chemical composition of Steel VM12-SHC [4]

\begin{tabular}{|c|c|c|c|c|c|c|c|c|c|c|c|}
\hline \multicolumn{10}{|c|}{ Skład chemiczny, \% } \\
\hline C & Si & Mn & Cr & Mo & V & W & Co & B & N & Nb & Ni \\
\hline 0,13 & 0,47 & 0,27 & 11,54 & 0,24 & 0,26 & 1,44 & 1,47 & 0,0045 & 0,048 & 0,044 & 0,27 \\
\hline
\end{tabular}

Tablica II. Skład chemiczny spoiwa według atestu producenta

Table II. Chemical composition of filler material

\begin{tabular}{|c|c|c|c|c|c|c|c|c|c|c|c|}
\hline \multicolumn{10}{|c|}{ Skład chemiczny, \% } \\
\hline C & Si & Mn & Cr & Mo & V & W & Co & B & N & Nb & $\mathrm{Ni}$ \\
\hline 0,14 & 0,53 & 0,35 & 11,3 & 0,3 & 0,22 & 1,4 & 1,6 & 0,003 & 0,04 & 0,06 & 0,5 \\
\hline
\end{tabular}


Parametry programu spawania przyjęto wg rekomendowanych wielkości opisanych w instrukcji obsługi oraz programowania źródła prądu typu PS 406.

Po spawaniu złącze chłodzono do temperatury $20 \div 100{ }^{\circ} \mathrm{C}$ w czasie powyżej dwóch godzin. Następnie przeprowadzono operację miejscowego wyżarzania odprężającego zgodnie z zaleceniami producenta stali Vallourec \& Mannesmann (rys. 3).

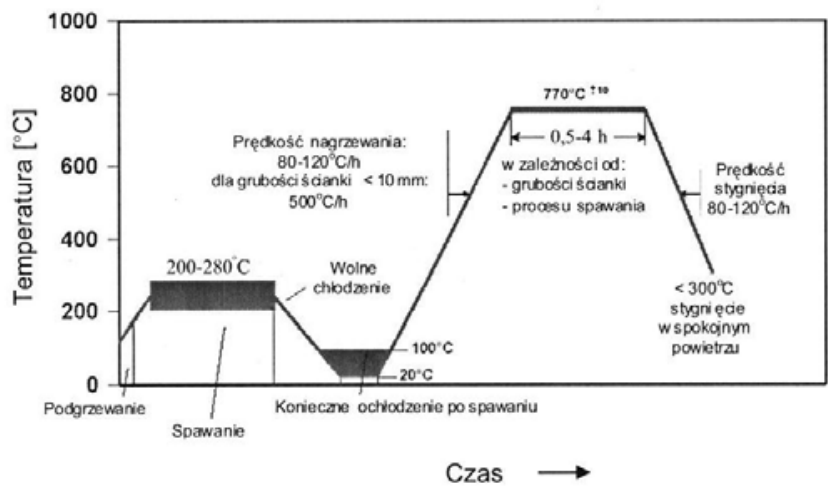

Rys. 3. Schemat cyklu spawania i obróbki cieplnej stali VM12-SHC [4] Fig. 3. Scheme of welding cycle and heat treatment of steel VM12-SHC [4]

\section{Badania nieniszczące}

Wykonane złącze próbne poddano badaniom nieniszczącym VT, PT i RT z uwzględnieniem poziomu jakości B według normy PN-EN ISO 5817. Badane złącze próbne charakteryzowało się regularną powierzchnią spoiny bez podtopień i nadlewów, podobnie sytuacja się przedstawiała w grani spoiny, którą przebadano z wykorzystaniem endoskopu. Równie pozytywne obraz złącza dało badania PT. Badania radiograficzne potwierdziły wysoką jakość wykonanego złącza (rys. 4).

Pozytywne wyniki badań nieniszczących dowodzą dużej jakości oraz powtarzalności złącz wykonywanych z wykorzystaniem techniki spawania orbitalnego. Przeprowadzone próby wskazują również na konieczność bardzo dokładnego przygotowania materiałów do spawania. Zalecanym sposobem przygotowania krawędzi złącza jest zastosowanie ukosowania na U, wraz z podtoczeniem wewnętrznym rury w celu uzyskania jednakowej wysokości progu na obwodzie złącza zwłaszcza w przypadku braku odpowiedniej owalizacji przekroju łączonych rur. Ten sposób przygotowania zmniejsza ryzyko występowania niezgodności w warstwach graniowych tj. nieregularnego przetopu czy też podtopień. Przyczyną nieregularnego przetopu lub wklęśnięcia grani może być również przygotowanie złącza wg szczegółu na $\mathrm{V}$ bez podtoczenia wewnętrznego oraz bez progu.

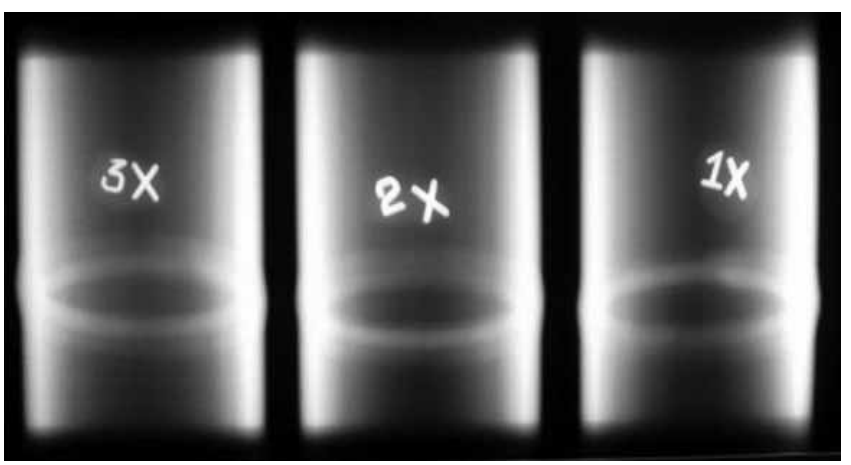

Rys. 4. Radiogram badanego złącza spawanego

Fig. 4. Radiogram of welded joint

\section{Badania niszczące}

Po uzyskaniu pozytywnych wyników badań nieniszczących, ze złącza spawanego zostały pobrane próbki do badań niszczących zgodnie z zaleceniami obowiązujących norm.

Zakres badań niszczących obejmował:

- Statyczną próbę rozciągania złącza spawanego wg PN-EN ISO 4136:2013-05,

- Próbę zginania (zginanie od strony lica oraz grani) wg PN-EN ISO 5173:2010,

- Badanie udarności (karb nacięty w spoinie, SWC oraz w materiale rodzimym) wg PN-EN ISO 148-1,

- Pomiary twardości wg PN-EN 1043-1

Statyczna próba rozciągania złącza

Badania przeprowadzono w celu określenia wytrzymałości złącza spawanego na rozciąganie oraz porównaniu

Tablica III. Wyniki próby statycznego rozciągania

Table III. The results of static tensile test

\begin{tabular}{|c|c|c|c|c|c|}
\hline \multirow{2}{*}{ Nr próbki } & \multirow{2}{*}{ 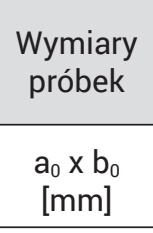 } & \multicolumn{2}{|c|}{ Wytrzymałość na rozciąganie } & \multirow{2}{*}{$\begin{array}{l}\text { Miejsce } \\
\text { zerwania }\end{array}$} & $\begin{array}{l}\text { Wymagania wg } \\
\text { VdTÜV }\end{array}$ \\
\hline & & $\begin{array}{l}\mathrm{Fm} \\
{[\mathrm{N}]}\end{array}$ & $\begin{array}{c}\mathrm{Rm} \\
{[\mathrm{MPa}]}\end{array}$ & & \multirow{3}{*}{$\mathrm{Rm}=620 \div 850 \mathrm{MPa}$} \\
\hline 1 & $14,1 \times 6,9$ & 555000 & 795 & \multirow{2}{*}{ poza spoiną } & \\
\hline 2 & $14,0 \times 6,8$ & 595000 & 815 & & \\
\hline
\end{tabular}

Tablica IV. Wyniki próby statycznego zginania

Table IV. The results of the static bending

\begin{tabular}{|c|c|c|c|c|c|}
\hline \multirow{2}{*}{ Oznaczenie próbki } & \multirow{2}{*}{$\begin{array}{c}\begin{array}{c}\text { Wymiary } \\
\text { próbki }\end{array} \\
a_{0} \times b_{0} \\
{[\mathrm{~mm}]}\end{array}$} & \multicolumn{2}{|c|}{ Kąt gięcia [º] } & \multirow{2}{*}{ Uwagi } & \multirow{2}{*}{ Wymagania } \\
\hline & & Lico & Grań & & \\
\hline GG1 & $14,0 \times 6,9$ & - & 180 & \multirow{4}{*}{$\begin{array}{l}\text { bez naderwań } \\
\text { i pęknięć }\end{array}$} & \multirow{4}{*}{$a \geq 130^{\circ}$} \\
\hline GG2 & $14,0 \times 6,8$ & - & 180 & & \\
\hline GL1 & $14,0 \times 6,9$ & 180 & - & & \\
\hline GL2 & $14,0 \times 6,8$ & 180 & - & & \\
\hline
\end{tabular}


otrzymanych wyników z właściwościami materiału rodzimego $(\mathrm{Rm}=755 \mathrm{MPa})$. Wynik próby przedstawiono $\mathrm{w}$ tablicy III.

Próbę statycznego zginania z rozciąganiem lica GL oraz grani GG wykonano zgodnie z PN-EN 15614-1 i PN-EN ISO 5173. Według postanowień normy, kryterium próby jest uzyskanie kąta $\geq 130^{\circ}$, bez wystąpienia rys i pęknięć na rozciąganej powierzchni próbki. Uzyskane rezultaty przedstawiono w tablicy IV.

Pomiary twardości przeprowadzono zgodnie z PN-EN 19952-6 oraz PN-EN 15614-1. Maksymalna twardość w wymienionych normach dla złączy obrobionych cieplnie wynosi 350 HV10. Na rysunku 6. przedstawiono wyniki pomiarów twardości, wszystkie zmierzone twardości są niższe od wartości dopuszczalnej.

Wyniki badań niszczących podobnie jak badania nieniszczące potwierdzają wysoka jakość otrzymanych złączy. Wszystkie badane właściwości charakteryzujące materiał złącza były na poziomie wyższym niż wymagają to odpowiednie normy przedmiotowe oraz nie przekraczały dopuszczalnych maksymalnych wartości. Przeprowadzone próby spawania przy założonych parametrach procesu i z wykorzystaniem spawania orbitalnego pozwoliły na opracowanie technologii spawania, która gwarantuje powtarzalną jakość otrzymywanych złączy. Kluczowym czynnikiem dla wyników badań niszczących jest również odpowiedni sposób postępowania ze stalą VM12-SHC po procesie spawania, czyli odpowiedni czas chłodzenia po spawaniu oraz obróbka cieplna według wytycznych producenta stali.

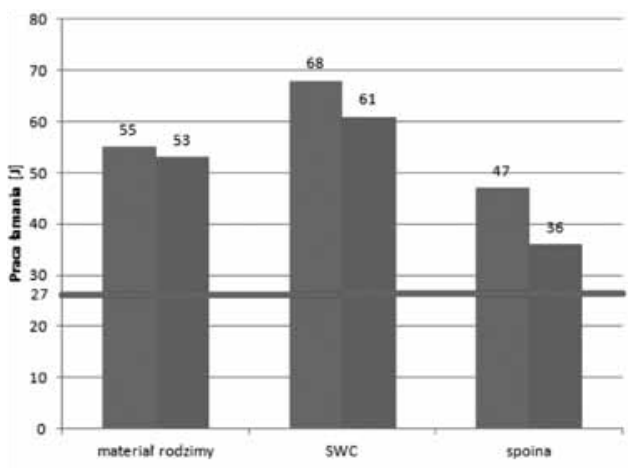

Rys. 5. Wyniki próby pracy łamania

Fig. 5. The results of impact tests

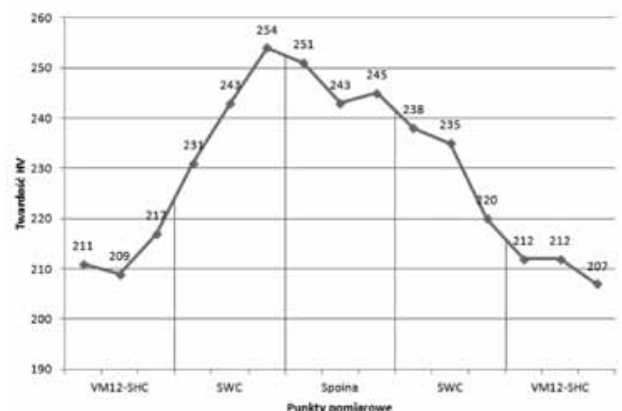

Rys. 6. Rozkład twardości w złączu spawanym ze stali VM12-SHC Fig. 6. The hardness distribution in welded joint of steel VM12-SHC

\section{Podsumowanie}

Przeprowadzone próby spawania złącza doczołowego dowiodły, iż spawanie orbitalne metodą TIG jest procesem bardzo skutecznym pod względem powtarzalności oraz jakości wykonanych połączeń spawanych. Odpowiednio przygotowane oprogramowanie procesu spawania czy też bieżąca kontrola stanu technicznego urządzenia, powodują iż wskaźnik wadliwość wykonywanych złącz może być bardzo niski. Z tego względu metoda spawania orbitalnego TIG jest rekomendowana w przypadku, gdy spawane są elementy

w gatunkach o utrudnionej spawalności tj. VM12-SHC. Poprzez zmniejszoną ilość niezgodności spawalniczych unika się napraw, a co się z tym wiąże - powtórnych zabiegów cieplnych, które mogą pogorszyć własności użytkowe złącza oraz wpływają na wynik ekonomiczny przedsiębiorstwa. Minimalna ilość niezgodności spawalniczych znacząco wpływa na wysoką produktywność procesu.

Przeprowadzone próby spawania uwidoczniły również mankamenty technologii. Aby zapewnić powtarzalność w procesie spawania orbitalnego metodą TIG, należy zapewnić następujące warunki, które są klasyfikowane jako istotne:

- wyszkolony personel,

- jakość i powtarzalność przygotowania elementów do spawania,

- jakość materiałów dodatkowych oraz gazów osłonowych,

- odpowiednie przygotowanie elektrody wolframowej,

- optymalne pozycjonowanie i przygotowanie złącza - zapewnienie współosiowości łączonych elementów,

- sprawdzone oprogramowanie procesu.

\section{Literatura}

[1] M. Zeman, S. Błacha: Spawalne stale martenzytyczne żarowytrzymałe nowej generacji, Przegląd Spawalnictwa, Vol.86, Nr 4, s.51-61, 2014.

[2] E. Tasak, A . Ziewiec: Spawalność materiałów konstrukcyjnych. Tom 1 - Spawalność stali, Wydawanictwo JAK, Kraków, 2009.

[3] Poradnik inżyniera - Spawalnictwo; WNT, Warszawa 2003.

[4] Brochure VM12 -SHC Technical Data Sheet. Materiały informacyjne firmy Vallourec, 2015.

[5] J. Jasak, K. Wojsyk., G. Golański: Właściwości mechaniczne niejednorodnego złącza spawanego stali VM12/X20 po wyżarzaniu, Przegląd Spawalnictwa, Vol.87, Nr 4, s. 5-9, 2015.
[6] M. Urzynicok, K. Kwieciński, M. Szubryt: Doświadczenia przy wykonywaniu połączeń doczołowych ze stali martenzytycznej VM12-SHC, Przegląd Spawalnictwa, Vol. 81, Nr 11, s. 20-25, 2009.

[7] A. Kolasa, P. Cegielski, A. Oneksiak: Nowa głowice do orbitalnego doczołowego spawania rur metodą TIG, Przegląd Spawalnictwa, Vol. 84, Nr 3, s. 32-38, 2014. 